\title{
Alcântara Machado e Norman Rockwell - algumas relações formais e temáticas
}

\author{
Carolina Curassá Rosa ${ }^{1}$
}

\begin{abstract}
RESUMO: A presente pesquisa faz algumas análises comparativas entre o contista modernista brasileiro Antônio de Alcântara Machado e o ilustrador norte-americano Norman Rockwell. Baseada em teorias semióticas e nas intermidialidades, a pesquisa tenta relacionar divergências e convergências entre eles no âmbito formal e temático, elencando traços estilísticos, ideológicos e culturais.
\end{abstract}

ABSTRACT: This research makes some comparative analysis between Antônio de Alcântara Machado, the Brazilian modernist writer, and the American illustrator Norman Rockwell. Based on theories about Semiotics and Intermidiality, this research attempts to relate differences and similarities between them in formal and thematic dimensions; listing stylistic, ideological and cultural characteristics to do this.

PALAVRAS-CHAVE: Intermidialidade; Semiótica; Artes comparadas.

KEYWORDS: Intermidiality; Semiotics; Comparative arts.

\section{Introdução}

É possivel observar ao longo dos estudos literários que a arte nos fornece imenso arcabouço de reflexões, comparações e análises, pois mostra ser reflexo de anseios, contextos sócio-econômico-culturais, de temas recorrentes em todas as eras e observados na produção da maioria dos artistas. Temas como o amor, o ódio, a morte e a vida

1 Aluna do programa de mestrado da Universidade Estadual Paulista - Unesp campus São José do Rio Preto. Título da dissertação: Alcântara Machado e Norman Rockwell - a arte de descrever sociedades. 
sempre exercerão uma atração sobre os artistas, pois revelam a essência humana.

Nesse sentido temático, a cidade se revela como tema importante na obra de grandes autores modernos. A partir do início do século XX, os habitantes da cidade passam a observar profundas transformações em seu dia a dia. Surge o carro, que fica cada dia mais rápido. O bonde faz parte das idas e vindas, principalmente dos trabalhadores braçais e funcionários das fábricas, que são uma novidade advinda da Revolução Industrial. Há mais fumaça, mais movimento, mais cores e mais perigos nas ruas da cidade. É claro que isso não passou despercebido aos olhos do artista.

O contista descreve essas mudanças em prosa, e o pintor, em ilustrações. O presente estudo pretende analisar um pouco esses olhares por meio de um conto de Alcântara Machado e uma ilustração de Norman Rockwell.

A partir dessa proposta, muitos perguntarão: mas como esses artistas podem ser relacionados? Ora, a linguagem é a única maneira de unir pessoas, temas e estudos, e por meio dela, propomos um estudo comparativo entre conto e ilustração. É com a linguagem que adentramos em diversos campos da literatura e nos estudos entre artes. A partir daí, observamos uma série de teorias e análises relacionadas à comparação de temas, expressões artísticas e formas.

\section{Semiótica}

A semiótica amplia o processo de leitura. Segundo Santaella (1999), a semiótica é o estudo de todas as linguagens possiveis e, assim, há muitos gêneros em que textos verbais e visuais são combinados e inter-relacionados de várias maneiras. Com isso, os leitores podem efetuar operações que não realizariam se decidissem que tal leitura não seria possivel (CLÜVER, 2006). 
A semiótica, para Greimas, baseava-se nas questões do estudo do discurso. Ele afirma que uma estrutura narrativa pode se manifestar em qualquer tipo de texto. Suas ideias influenciaram a Escola de Paris e se tornaram altamente produtivas. Sua concepção de discurso aplica a linguística estrutural na análise de textos e se opõe à teoria semiótica como teoria dos signos. Segundo Nöth (1996), a semiótica para Greimas deveria ser uma "teoria da significação". Para isso, Greimas propõe o percurso gerativo de sentido, pelo qual explica a geração de discursos de qualquer sistema semiótico.

No que tange ao processo gerativo greimasiano, Fiorin (1994) explica que a manifestação é a união de um plano de conteúdo a um plano de expressão. Quando se manifesta um conteúdo por um plano de expressão, surge um texto.

Portanto, é possivel analisar os discursos dos artistas selecionados, comparando seus traços estilísticos e seus níveis de estrutura elementar da significação. Logo, pode-se observar como estes artistas valorizam a cor local, o movimento social, as transformações históricas e ideológicas de sua sociedade. A revolta de uma geração, o ápice da produção da cultura de massa norte-americana, tudo isso envolve questões internas e externas aos artistas e a maneira como a sociedade influencia sua produção artística.

\section{A correspondência entre artes e intermidialidade}

Até o Renascimento, a importância dada a algumas artes verbais, como a poesia e a retórica, modificou-se. Com isso, a pintura, a escultura e outras artes visuais passaram a ser vistas com a mesma igualdade e importância valorativa das artes verbais. Segundo Ribeiro (2001), a semiótica constata essas afinidades entre os signos e os tipos de textos, supera ambiguidades das antigas terminologias e introduz 
novos pontos de vista ao antigo sistema clássico de divisão entre as artes.

O estudo das artes evoluiu. Observam-se, com isso, em pesquisas recentes, avanços no que se trata de estudos entre artes e semiótica. Dentre esses avanços, encontra-se o estudo da intermidialidade, que introduz novos pontos de vista ao sistema clássico de análise entre as artes e o da semiótica.

A intermidialidade expande o olhar do pesquisador das artes comparadas para mostrar que toda arte pode ser considerada mídia, pois passa uma mensagem que recorre a todo um aparato cultural para produzi-la. Os discursos vistos sob a luz dessa teoria vão além da capacidade expressiva de um só meio.

Clüver, um dos principais teóricos sobre esses estudos, ainda considera a semiótica importante em suas análises. Mas não seguindo o padrão da última fase de Peirce, em que tudo é entendido como signo, pois isso enfatiza de maneira exagerada os conceitos e procedimentos semióticos no que se refere aos Estudos Interartes, especialmente quando associado ao ato de "ler" - o termo fica entre aspas, pois o autor o utiliza em sentido metafórico. O teórico recorre à semiótica como disciplina auxiliar que possibilita trabalhar com conceitos e designações transmidiáticas em muitas operações no campo dos Estudos Interartes, pois uma obra de arte é entendida como uma estrutura sígnica.

O autor expõe ainda, em um de seus artigos, o raio de abrangência desses estudos:

O leque dos Estudos Interartes parte dos estudos de fontes, passa por questões de periodicidade, problemas de gênero e transformações temáticas, até alcançar todas as formas possiveis de imitação que ocorrem através das fronteiras entre mídias (em formas e técnicas estruturais, tendências estilísticas e outras mais). Os Estudos Interartes abrangem, além disso, aspectos transmidiáticos como possibilidades e modalidades de representação, expressividade, narratividade, questões de tempo e espaço em representação e recepção, bem como o papel da performance e da recitação. (CLÜVER, 2006, p. 16) 
Portanto, expande as possibilidades de análise da literatura comparada, que considera muitos desses fatores e acrescenta elementos que podem definir melhor as mídias e suas expressões artísticas.

Molser (2006), ao abordar o objetivo desses estudos, afirma: "Trata-se de continuar buscando novas respostas, a fim de dar, mais ainda, a essa expressão o matiz semântico da intensificação que decorre mais de um processo do que da chegada a uma ideia definitiva" (MOLSER, 2006, p. 42).

Portanto, essa ciência será útil no sentido de demonstrar a possibilidade das comparações, a realidade das reflexões propostas e justificar o valor de tais questionamentos.

\section{Algumas análises}

Vale notar que, em termos de arte, o ethos humano, abordado por Hegel, se faz presente em todas as expressões artísticas. Temas como os já citados no início do estudo (morte, amor, ódio, angústia, traição) são muito recorrentes. Outro tema importante e que conecta obras e eras é o da transitoriedade urbana.

O ambiente urbano é visto em grande parte da obra dos dois autores, mostrando as mudanças em um nicho específico da sociedade brasileira - os imigrantes italianos em São Paulo - e a classe média da sociedade norte-americana com todos os seus anseios e desejos relacionados ao american dream. Como as artes, como já demonstrado através das teorias sobre os Estudos Interartes e sobre a intermidialidade, dialogam entre si, é possivel observar a ocorrência dessa urbis nos contos de Alcântara Machado e nas ilustrações de Norman Rockwell.

Através da problemática urbana, eles conseguem expressar as incessantes mudanças sociais, a paisagem movente e o ritmo frenético da cidade. 
Ao observar Baudelaire em suas reflexões sobre Paris e o homem moderno, notamos desde os primórdios do mundo industrializado essa preocupação do artista. Essas mudanças constantes desse novo mundo geram a destruição dos antigos valores, e o artista se vê forçado a construir novos paradigmas em meio às ruínas. Nesse sentido, Sebastião Uchôa Leite afirma que o artista, ao mesmo tempo em que busca o novo, é "Conservador," mas "nem por isso o poeta deixa de ver o novo mundo que surge em meio às ruínas do antigo" (LEITE, 2003, p. 14).

Ao longo da história da literatura, observa-se a cidade nas produções de artistas como Dostoiévski, Villoon, Turner, Poe, T.S. Elliot e outros. Chegando a um dos artistas analisados no presente estudo: Antônio de Alcântara Machado.

Segundo Luís Toledo Machado (1970), Alcântara Machado começou na literatura escrevendo peças de teatro para jornal. No ano de 1925, fez uma viagem à Europa e, assim, obteve inspiração para escrever crônicas e reportagens que viriam a dar origem ao seu primeiro livro: Pathé-Baby, prefaciado por Oswald de Andrade. Foi um dos fundadores da Revista de Antropofagia juntamente com Oswald de Andrade, em 1928, ano em que lançou a obra Laranja da China. Apesar de não ter participado da Semana de Arte Moderna, era, de fato, um modernista, investindo na desconstrução das convenções clássicas e na descrição de uma identidade e linguagem definitivamente brasileiras. Para isso, fazia uso de uma linguagem leve, bem-humorada e espontânea, certamente influenciada pelo seu passado como jornalista. Alcântara Machado talvez tenha sido um dos primeiros artistas brasileiros a usar o elemento gráfico como expressão literária aplicada à prosa de temas urbanos do cotidiano. Além disso, em 1926, também foi cofundador da revista Terra Roxa e Outras Terras, além de colaborar com a Revista Nova.

Ainda segundo Luís Toledo Machado (1970), esse representante da geração modernista foi um dos eixos de uma mudança de mentalidade e de consciência frente à realidade brasileira e universal. 
Em sua obra Cavaquinho e Saxofone, que compreende a produção do autor para jornais e revistas, publicada postumamente em 1940, Alcântara Machado estabelece a divisão que ocorreu na consciência cultural do país entre velhos e moços. Fica evidente em suas obras a incompreensão e a impossibilidade de qualquer entendimento entre gerações, e ele justifica a necessidade da destruição de velhas ideias. Havia um culto à "coragem de afirmar destruindo". Diante desse sentimento de desolação do grupo de intelectuais do país, Antônio de Alcântara Machado escreve:

A rapaziada de minha idade, que abriu os olhos já neste século, cresceu e se formou num ambiente feito de desânimo, de tragédia e de negação. Principiou encontrando a República desmoralizada. Lendo os jornais ou ouvindo a conversa dos mais velhos aprendia a xingar os administradores e odiar os politicos. Tudo podre, tudo péssimo, o país governado por ladrões e ineptos e apesar disso sustentando-os no mando (MACHADO, 1940, p. 330).

Assim, foi essa geração que inaugurou o nosso século XX e pode ser considerada decisiva, pois produziu uma nova imagem da vida, modificou um sistema de valores sociais e estéticos e inaugurou novas tendências na história do pensamento literário e artístico brasileiro. Nosso autor alcança esse fenômeno que perduraria até um espaço intermediário entre a primeira e a segunda guerra mundiais.

O estilo moderno de Alcântara Machado também aborda a cidade como tema de sua arte em toda a sua complexidade, demonstrando toda a sua vontade de alcançar o novo, de romper com as tradições. Isso vem embutido de todo um senso de ruptura.

Com sua linguagem direta, objetiva, quase telegráfica e abordando um nicho social marginalizado - os imigrantes italianos Alcântara alcança seu objetivo ao expressar uma densa sucessão de fatos e valores em formato de conto, uma estrutura também não muito explorada na época.

Observemos o seguinte trecho do conto Lisetta, em Brás Bexiga e Barra Funda: 
Quando Lisetta subiu no bonde (o condutor ajudou) viu logo o urso. Felpudo, felpudo. E amarelo. Tão engraçadinho.

Dona Mariana sentou-se, colocou a filha em pé diante dela.

Lisetta começou a namorar o bicho. Pôs o pirulito de abacaxi na boca. Pôs mas não chupou. Olhava o urso. O urso não ligava. Seus olhinhos de vidro não diziam absolutamente nada. No colo da menina de pulseira de ouro e meias de seda parecia um urso importante e feliz.

- Olha o ursinho que lindo, mamãe!

- Stai zitta! (MACHADO, 1940, p. 52)

Neste excerto já se observa a presença do bonde, as diferenças sociais, as palavras bem escolhidas para que uma imagem rica em detalhes seja expressa com palavras contadas e sejam produzidas frases curtas. Apenas em algumas linhas notamos sua objetividade e sua visualidade demonstradas na textura e cor do urso (felpudo e amarelo), no sabor de um pirulito, nos acessórios da menina rica, nos diminutivos para expressar melhor o sentimento da personagem e, claro, as palavras em italiano (tradução: "Fique quieta!") que mostram a oralidade e evidenciam a origem da personagem.

Ao longo do conto, o enredo trabalha com a vontade de Lisetta de brincar com o ursinho. Mas a menina rica e egoísta apenas exibe ainda mais seu bem e mostra que sua condição é inatingivel para a criança pobre. Lisetta, como toda criança, chora para conseguir o que deseja, mas o que recebe em troca é uma punição da mãe que cessa apenas com a intervenção de um irmão mais velho. Este irmão, mais tarde, dá um urso a Lisetta, menor, inferior ao da menina rica, mas é dela. A ironia se manifesta no final, quando o egoísmo é premiado. Sim, a menina rica não sofre por não dividir. Já Lisetta é castigada por pedir o urso, envergonhando sua mãe italiana que veio ao Brasil para enriquecer, e não para ser pobre e, além disso, sua filha chamar atenção para sua condição.

O conto termina com as seguintes palavras:

- Tome pra você. Mas não escache. 
Lisetta deu um pulo de contente. Pequerrucho. Pequerrucho e de lata. Do tamanho de um passarinho. Mas urso.

Os irmãos chegaram-se para admirar. O Pasqualino quis logo pegar no bichinho. Quis mesmo tomá-lo à força. Lisetta berrou como uma desesperada:

- Ele é meu! O Ugo me deu!

Correu para o quarto. Fechou-se por dentro (MACHADO, 1940, p. 56).

É interessante notar a carga de ironia no final do conto quando o egoísmo é recompensado e praticado. Portanto, tais menções do conto e sua leitura mostram como a linguagem bem trabalhada esboça temas profundos e desenha cenas claras e coloridas mesmo com poucas palavras - isso se levarmos em conta algumas teorias do conto que o define como um texto menor, como a de Poe, estudada por Cortázar, que por algum tempo foi muito influente: a de que o conto é uma narração curta em prosa, definindo o conto breve como uma peça literária que requer pouco tempo de leitura (CORTÁZAR, J., 1974).

Essas leituras e traços formais nos remetem às teorias da semiótica e da intermidialidade, pois os valores culturais, históricos e sociais, suas características físicas (textura e saturação das cores) e espaciais, dentro da materialidade textual (posição das imagens e uso das palavras) são importantes tanto no conto quanto nos quadros. Os planos de conteúdo e de expressão remetem à linguagem como um sistema de significação composto por signos verbais e não verbais que produzem efeitos de sentido dentro do sistema (discurso) em que estão inseridos, considerando suas características históricas, sociais e temporais, bem como aquelas dos indivíduos envolvidos no processo de interação.

Dentro dessa abordagem, o conto mencionado e as ilustrações que serão analisadas em seguida criam uma só perspectiva quando lidos sob a óptica de tais teorias, pois, além da forma e da temática, expressam motivações do signo verbal ou não verbal semelhantes, existente entre o plano de expressão e do conteúdo. 
Passamos, então, a analisar essas características (objetividade, linhas bem definidas, linguagem clara, ironia e temática urbana e social) em Norman Rockwell. Todas elas são bastante visíveis ao contemplarmos uma de suas ilustrações, mas a ironia não se faz tão evidente assim. Em sua obra, a ironia como traço estilístico é bastante sutil, mas evidente quando observamos retratos que mostram situações perfeitas, pessoas felizes e crianças rosadas em uma era de transições, guerras e do crack da bolsa de Nova York.

É necessário descrever alguns dados sobre o pintor norteamericano para melhor esclarecer suas escolhas e o discurso de suas ilustrações.

Nascido em 1894, em Nova York, Norman Rockwell foi um pintor e ilustrador muito popular nos Estados Unidos, especialmente em razão das 323 capas da revista publicadas no The Saturday Evening Post, uma das revistas que melhor expressaram a cultura popular norteamericana, seus valores, anseios e desejos. O ilustrador teve uma vida longa, morreu em 1978, em consequência de um enfisema.

Enquanto o principal tema de Alcântara Machado eram os imigrantes italianos, segundo o site oficial de Rockwell ${ }^{2}$, o principal assunto do pintor foi a América e as pessoas que vivem nela. Muitos historiadores consideram que sua obra representa uma crônica da sociedade americana, seus sonhos e aspirações.

Segundo o próprio Norman Rockwell, "I showed the America I knew and observed to others who might not have noticed"3 (Site oficial de Norman Rockwell).

Vale lembrar que a ironia, de acordo com autores como Muecke (1995), Knox (2005) e Hutcheon (1994), é um procedimento que pode ser definido por dizer o contrário daquilo que se pensa, deixando entender uma distância intencional entre aquilo que se enuncia e aquilo que realmente se pretende explicitar na enunciação. Ela se dá a partir

\footnotetext{
2 <http://www.rockwelllicensing.com> Última consulta em 10 de março de 2011.

"Eu mostrei a América que conhecia e observava a outros que talvez não a tivessem notado".
} 
da incongruência entre o dito e o não-dito, levando-se em conta a situação enunciativa, bem como as características próprias do personagem ironizado e da pretensão do ironista. Por esse caráter dúbio, a ironia tende a buscar uma reação no leitor com o objetivo de denunciar, criticar ou censurar algo. Para isso, o artista descreve a realidade com termos que aparentemente valorizam a realidade, mas, na verdade, têm a finalidade de desvalorizá-la, o que convida o leitor a interagir com o texto proposto, visando refletir sobre o tema.

Nesse sentido, as ilustrações de Norman Rockwell são bastante irônicas por deixar subentendidas várias reflexões e, além disso, suas técnicas vão contra a corrente de todas as tendências contemporâneas a ele, como futurismo, cubismo, expressionismo e surrealismo, entre outras.

Com o foco nos detalhes, nas linhas precisas, nas cores bem definidas, ele trabalha problemas sociais norte-americanos, como a pobreza velada, o proletariado sempre oculto, as decepções e conflitos políticos e a segregação social e racial.

Um dos quadros de Rockwell que demonstra as contradições do homem moderno com funções típicas da cidade é The Jesters (1939). 


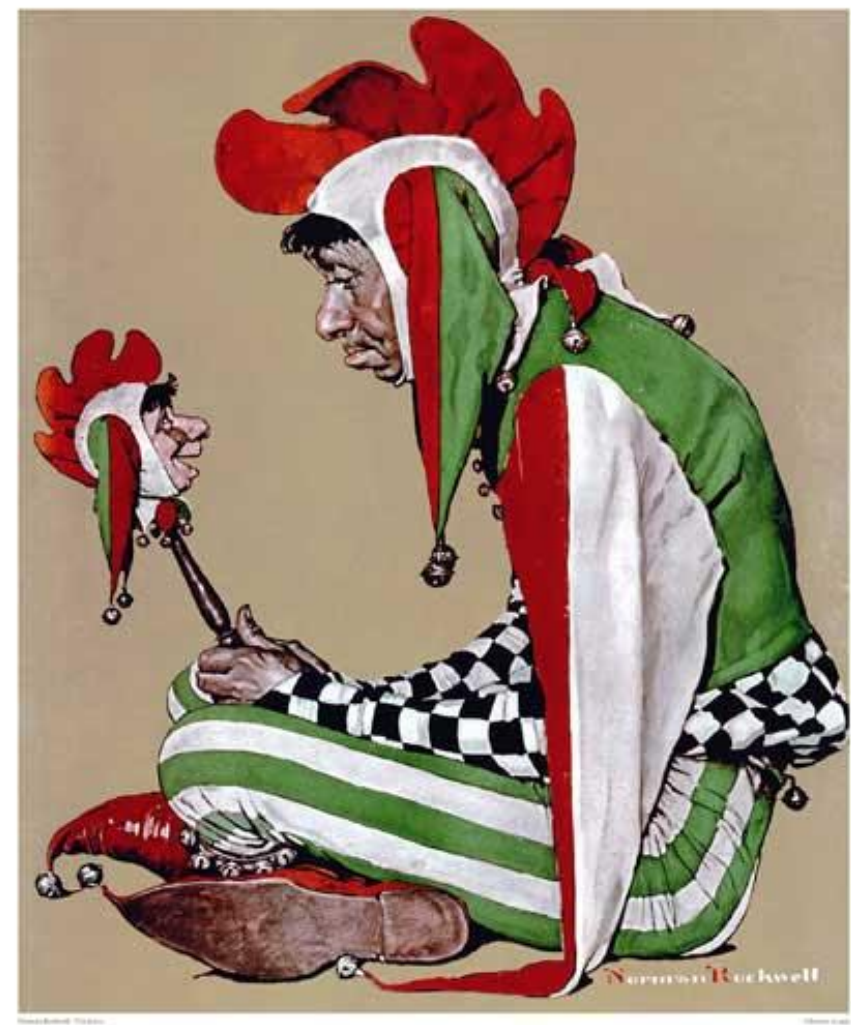

Após dez anos do crack da bolsa de Nova York, a II Guerra Mundial estava no início. Os conflitos são inegáveis e não há como fugir deles. O nivel fundamental do discurso remete a alguns questionamentos interessantes. O palhaço, símbolo de alegria, mira sua réplica sorrindo, mas não consegue sorrir também. Seria por mera insatisfação do objeto visto ou, talvez, um sentimento mais profundo de insatisfação com tudo ao seu redor? Além das expressões faciais, observam-se contrastes, uma série de oposições, nas categorias semânticas que estão na base da construção do texto visual: as cores vibrantes e traje arrojado contrastam com a postura arqueada do palhaço. O american dream parece revelar-se apenas um sonho para ele, um molde de valores impulsionados pelo consumismo massificado, mas que nem sempre consegue satisfazer a todos. Isso porque é fácil se esquecer do indivíduo como tal, que lida com conflitos internos e externos. Entretanto, isso não escapa aos olhos do artista.

Norman Rockwell é considerado um dos maiores contadores da história dos Estados Unidos. De fato, ele o é. Contudo, é preciso ser 
menos ingênuo ao analisar suas obras para notar que toda aquela perfeição não é real, que sua arte vai além da mensagem que nos é mostrada num primeiro olhar.

Com isso, conclui-se que há, sim, divergências entre os artistas. O brasileiro rompe tradições, o norte-americano prefere seguir moldes clássicos. Um ironiza com força a sociedade paulistana; o americano faz isso com sua sociedade também, mas sutilmente. Porém, ambos mostram características similares como a objetividade das formas, a própria ironia e sua temática popular.

Portanto, as artes se mostram, mais uma vez, inter-relacionadas e não dependem, necessariamente, de os artistas influenciarem um ao outro de maneira direta. E as reflexões sobre isso não se detêm aqui, mas seguem os muitos questionamentos da linguagem, os percursos do olhar e as reflexões de um grande leque de leituras possiveis.

\section{Referências Bibliográficas}

CANDIDO, Antônio. Literatura e sociedade. São Paulo: 3a. ed., São Paulo: Cia. Editora Nacional, 1973.

CARVALHAL, Tânia. Literatura comparada. São Paulo: Ática, 1986.

CHAUÍ, Marilena. O que é ideologia. Digitalizado em 2004. Disponível em http://www.scribd.com/doc/12876624/Colecao-PrimeirosPassos-O-Que-e-IdeologiaMarilena-Chaui. Acesso em: 10 de jul. de 2010.

CLÜVER, Claus. Da transposição intersemiótica. In. ARBEX, Márcia (Org.) Poéticas do visivel - ensaios sobre a escrita e a imagem. Belo Horizonte: Faculdade de Letras da UFMG (FALE), 2006.

Inter textus/ inter artes/ inter media. Org. CLÜVER, Claus et al. In. Aletria - revista de estudos de literatura, v. 6. Belo Horizonte: POSLIT/FALE/UFMG, 1998/99.

COLI, Jorge. O que é arte? São Paulo: Brasiliense, 1981. 
CORTÁZAR, Julio. Alguns aspectos do conto. São Paulo: Perspectiva, 1974.

COUTINHO, E.; CARVALHAL, T. (Orgs.) Literatura comparada: textos fundadores. Rio de Janeiro: Rocco, 1994.

FIORIN, José Luiz. Elementos da análise do discurso. São Paulo: Contexto, 1994.

GONÇALVES, Aguinaldo José. Laokoon revisitado. São Paulo: Edusp, 1994.

HEGEL, Friedrich. Cursos de Estética. São Paulo: Edusp, 2002. Vol. 3.

HUTCHEON, Linda. Irony's edge: the theory and politics of irony. London/ New York: Routledge, 1994.

KNOX, Norman D. Irony. In: Dictionary of the History of Ideas. New York: Philip P. Wiener, 1973, vol. II, p. 626-634. Disponivel em: < www.etext.lib.virginia.edu/cgilocal/DHI/dhi.cgi?id=dv2-70 - 59k $\rightarrow>$ Último acesso em: 16 mar. de 2010.

LEITE, Sebastião Uchôa. Críticas de ouvido. São Paulo: Cosac Naify, 2003.

MACHADO, Antônio de Alcântara. Novelas Paulistanas. Rio de Janeiro: Expressão e Cultura, 2001.

. Cavaquinho e Saxofone. Rio de Janeiro: Livraria José Olympio, 1940.

MACHADO, Luis Toledo. Antônio de Alcântara Machado e o modernismo. São Paulo: José Olympio, 1970.

MUECKE, Douglas Colin. Ironia e o irônico. Tradução: Geraldo Gerson de Souza. São Paulo: Perspectiva, 1995.

MOSER, Walter. As relações entre as artes: por uma arqueologia da intermidialidade. Org. CLÜVER, Claus et al. In. Aletria - revista de estudos de literatura, v. 6. Belo Horizonte: POSLIT/FALE/UFMG, $1998 / 99$. 
PIETROFORTE, Antonio Vicente. Semiótica visual: os percursos do olhar. São Paulo: Contexto, 2004.

RIBEIRO, Eunice. Ver. Escrever - José Régio, o texto iluminado. Braga: Universidade do Minho, 2000.

SANTAELLA, Lúcia; NÖTH, Winfried. Imagem: cognição, semiótica, mídia. São Paulo: Iluminuras, 1999.

Site Oficial de Norman Rockwell. Disponível em <http://www.rockwelllicensing. com/nr_gallery.html>. Acesso em 13 de ago. de 2010.

TAVARES, Hênio. Teoria literária. São Paulo: Itatiaia, 2002. 